\title{
Incentivos governamentais e indústria de defesa
}

\author{
Public incentives \\ and defense industry
}

Rev. Bra. Est. Def. v. 3, nº 2, jul./dez. 2016, p. 177-196

ISSN 2358-3932

THIAGO PACHECO

LUIZ PEDONE

\section{INTRODUÇÃO}

A necessidade de investir no desenvolvimento do setor industrial de Defesa e Segurança motivou administrações mais recentes no Brasil a formularem políticas públicas voltadas para a Base Industrial de Defesa (BID), como projetos de desenvolvimento de produtos de defesa, linhas de financiamento e regime tributário especial para o setor. As iniciativas objetivaram a melhoria do ambiente de negócios dessa indústria.

Este artigo avaliou a relação histórica Estado-Indústria de Defesa no Brasil, sumarizando as principais evidências encontradas em relação a incentivos governamentais e desenvolvimento da indústria de defesa. A pesquisa buscou identificar as medidas de incentivo mais recentes para essa indústria e analisar a percepção do setor privado quanto à atratividade do setor através de uma revisão histórica. Em outras palavras, a finalidade do trabalho foi de avaliar se as medidas públicas estimulam a indústria de defesa, de empresas públicas e privadas, ao fazê-las verem esse setor como um polo de oportunidades.

\footnotetext{
Thiago Pacheco - Formado em Relações Internacionais pela UFF (2016) e é membro do Grupo de Pesquisa Defesa, Ciência E Tecnologia e Política Internacional. E-mail: thiago_pacheco@id.uff.br.

Luiz Pedone - Professor de Relações Internacionais e Políticas Públicas no Instituto de Estudos Estratégicos da UFF e coordenador do referido Grupo de Pesquisa (registrado no CNPq). E-mail: lpedone@uol.com.br.

A pesquisa originária deste artigo culminou na monografia $O$ Impacto dos Incentivos na Expansão e no Declínio da Indústria de Defesa Brasileira: O Caso da Inserção de Grandes Conglomerados (Pacheco 2016), orientada por Luiz Pedone. Este artigo resume os principais pontos do estudo histórico do trabalho.
} 


\section{INCENTIVOS DO ESTADO E INDÚSTRIA DE DEFESA}

A relação entre a Indústria de Defesa e Estado pode ser mais bem compreendida ao observar a dinâmica que rege a BID. Brick (2014) observou nesse mercado que as firmas atuam nos segmentos de defesa, de segurança e também no civil, pois a maioria das empresas aplica suas tecnologias e produtos para uso civil de modo a sustentar a produção para os outros dois mercados. O segmento civil segue leis de mercado tradicionais - oferta e demanda, fornecedores e compradores competindo pelo melhor custo-benefício; contudo, as leis de mercado não prevalecem no segmento de defesa. Fora das Forças Armadas não há demanda da maioria dos produtos estratégicos - exceto produtos específicos, como armas e munições pequenas - sendo este mercado caracterizado como praticamente monopsônico, o Estado como único comprador (Brick 2014). Se considerados os outros Estados, o mercado pode ser visto como oligopsônico, sem concorrência efetiva.

A demanda de produtos de defesa é determinada principalmente por fatores estratégicos e geopolíticos dos Estados, não pela lógica econômica (ABDI 2011), tornando esse o principal componente para definir a produção das empresas.

Da mesma forma como o Estado é responsável pela demanda do segmento de defesa, ele é o grande incentivador da BID, pois tem como função sustentar a demanda por produtos através de projetos militares e, portanto, tem a capacidade de alocar os seus recursos para garantir orçamento contínuo e que corresponda a ou amplie a dimensão da indústria (Brick 2014).

Hartley (1999) também ressaltou que o Estado pode usar seu poder regulatório e de compra (defense procurement) para definir a estrutura da indústria de Defesa, seu tamanho, as empresas que nele entram ou saem, as metas tecnológicas, preços e lucros deste setor industrial.

Segundo Mowery (2012), existem três formas que o Estado pode incentivar (ou restringir) a indústria de defesa privada ou estatal, o que a torna tão próxima dos governos nacionais:

a) oferecendo previsibilidade e segurança quanto aos investimen$\operatorname{tos}^{1}$ - o dispêndio não instável ou não declinante do Estado em Defesa garante maior segurança para o seu setor industrial, pois os programas de Defesa demandam tempo, levando anos ou décadas para serem concluídos e, portanto, contando com riscos por ter o investimento em P\&D como suporte (Drumond 2014; Mowery 2012);

b) o fomento da inovação - efeito ocasionado através da transferência de tecnologia ou do spin-off, pois o investimento por parte do Estado 
encorajaria o desenvolvimento científico e tecnológico, que possibilitaria impactos no nível tecnológico e nos processos produtivos das empresas; e

c) através das compras públicas - instrumento estatal que também foi estudado por Gunnar Eliasson (2010), que entendeu que public procurement seria a política industrial mais efetiva para P\&D de Defesa. Diretamente, as compras públicas de Defesa estimulariam um crescimento pela demanda, tendo o Estado como maior beneficiário do valor social dos produtos comprados, substituindo a demanda do mercado e, posto que o Estado é um comprador avançado - um comprador com conhecimento técnico, capaz de influenciar no desenvolvimento do produto final -, as compras estimulariam maior nível tecnológico e produtivo (Eliasson 2010, 4). Indiretamente, Eliasson se centrou nos efeitos multiplicadores dos programas de compras públicas, incluindo também o spin-off, originado durante a fase de desenvolvimento do produto, mas que fica disponível para os setores industriais proporcionalmente à capacidade empresarial de identificar os transbordamentos e comercializá-los (Eliasson 2010).

\section{INCENTIVOS DO ESTADO À BID NO BRASIL}

\section{Período Anterior à Era Vargas}

Até o início da República, as atividades industriais no âmbito das Forças Armadas limitavam-se a arsenais estatais para produção de material, como armas, munições ou mesmo navios. Quando a República foi estabelecida, grande parte dos militares passou a se engajar mais nos assuntos políticos e a demandar o reequipamento das Forças Armadas (Drumond 2014). Nos governos de Deodoro e Peixoto, a responsabilidade de fornecimento continuou centrada no Estado Brasileiro, mas não pelo incentivo da produção em suas fábricas militares e sim pela importação de equipamento, principalmente, da Europa, sendo que as compras de estrangeiros não conferiram capacidade de manutenção às FAs, ou seja, logo os produtos adquiriam baixo valor operacional (Drumond 2014).

Os governos civis seguintes da República Velha não destoaram dessas práticas, pois a diretiva foi "importar os armamentos necessários e estabelecer, nos arsenais, oficinas para a montagem e manutenção dos mesmos" (Amarante 2004, 24). Sobretudo com o fim da $1^{\text {a }}$ Guerra, que encheu o mercado internacional com armamentos excedentes a preços mais baixos, era mais atrativo e menos custoso para o Estado comprar internacionalmente do que investir na infraestrutura de uma BID, ainda mais por conta do caráter da indústria de ser vista como um setor subordinado frente aos interesses de uma economia cafeeira e agroexportadora (Drumond 2014). 


\section{Era Vargas}

A ascensão de Vargas ao poder consolidou a opção por uma política de proteção à indústria em geral. A industrialização tornou-se pauta importante para modernização e crescimento da economia brasileira, germinando o paradigma desenvolvimentista - ótica do Estado empresário, propulsor da indústria, adotando a substituição de importações e buscando superar os entraves e constrangimentos externos (Leopoldi 2000, 288). O governo atuou fomentando a indústria principalmente com políticas setoriais que envolviam tarifas, câmbio, controle de importações de equipamentos e criação de uma indústria de infraestrutura, como siderurgia e metalurgia, que é base para toda a indústria, bem como conferiu organização às relações trabalhistas na indústria (Leopoldi 2000).

Com o crédito mais fácil para as indústrias e as proteções mais altas, além do câmbio mais desvalorizado e os lucros mais atrativos no setor industrial que no agrícola, os empresários brasileiros foram estimulados a prosseguirem com seus esforços na indústria (Skidmore 2007). No setor de defesa, apesar de não haver um programa sólido, foram lançadas as bases para o crescimento setorial: de modo amplo, pelos incentivos à indústria de base e, em específico, pela mudança na característica das compras públicas. Nos anos subsequentes, o Estado passou a comprar, junto dos equipamentos, os desenhos e especificações técnicas, ou seja, passou a adquirir técnica e não apenas o produto final (Skidmore 2007).

Novas fábricas militares foram inauguradas - uma em 1932, quatro em 1933 e uma em 1939, totalizando seis - voltadas para produção de tecnologias estrangeiras, adquiridas ou licenciadas (Amarante 2004, 25), mantendo a produção de determinados equipamentos militares sob exclusividade da indústria de defesa estatal. A instalação da indústria siderúrgica no Brasil, incentivada pelo Estado brasileiro, permitiu que materiais mais pesados, como canhões e viaturas blindadas, fossem produzidos no país nas décadas posteriores (Amarante 2004). A iminência do confronto bélico entre as grandes potências mundiais, com o passar dos anos, fez Vargas focar ainda mais sua atenção na Defesa Nacional; devido ao tamanho do investimento no aparelhamento das FAs, "tudo indicava que o Brasil constituiria a mais poderosa máquina militar do América do Sul” (Drumond 2014, 66).

As empresas privadas começaram a surgir nessa época, como a Rossi e a Companhia Brasileira de Cartuchos (final de 1920), a Taurus (em 1937, hoje uma das maiores produtoras de armas do Brasil) e a Boito (que iniciou as atividades nos anos 1920, mas começou sua produção em série na década de 1950), sendo empresas majoritariamente de imigrantes europeus (Dreyfus et alii 2005). 


\section{Os Anos 50}

A $2^{\text {a }}$ Guerra impôs restrições às importações e, no pós-guerra imediato, com o Governo Dutra (1946-1951) que praticou plataforma mais liberal, as importações foram liberalizadas para, em primeiro lugar, reequipar com bens de capital ${ }^{2}$ a indústria brasileira e, em segundo, forçar os preços industriais para baixo com maior oferta de produtos importados (Vianna 1989). Segundo Furtado (1995), isso acabou extinguindo as reservas cambiais e, para corrigir o desequilíbrio de divisas, o Estado adotou uma série de controles seletivos de importação, favorecendo o setor industrial por duas vertentes: a redução da concorrência externa e a aquisição de matérias-primas e equipamentos a preços mais baixos, levando à intensificação da industrialização. Dutra, sucessor de Vargas, forneceu apenas o básico de estímulo industrial, sendo caracterizado como "pálido" para a BID (Drumond 2014).

O segundo Governo Vargas, apesar de imerso em atritos políticos e com a dificuldade de obtenção de financiamento externo pelas condições não tão favoráveis como no período pré-guerra, viu ainda assim o Banco Nacional de Desenvolvimento (BNDE, de 1952) como importante instrumento de fomento a industrialização sem, contudo, incluir na lista de investimentos a BID privada, ainda muito incipiente (Drumond 2014). O governo JK, porém, deu arrancada desenvolvimentista com o Plano de Metas baseado na aliança com o capital privado estrangeiro para reestruturação do parque industrial, com políticas protecionistas, resultando no famoso tripé Empresas Estatais/Indústrias Locais/Firmas Estrangeiras e em crescimento industrial de mais de 80\% (Leopoldi 2000).

Em específico para setor de Defesa, JK criou institutos de pesquisa tecnológica na Marinha e no Exército (Drumond 2014), como o Instituto de Pesquisas da Marinha, em 1959. Todavia, o governo seguinte de Jânio Quadros (janeiro a agosto de 1961) foi contracionista e reduziu gastos públicos. No período de incertezas de Jânio a 1964, "não se vislumbraram traços de uma política industrial” (Leopoldi 2000, 290). Paralelamente, com o contexto da Guerra Fria, o contato entre militares brasileiros e americanos desenvolveu em lideranças políticas e setores militares, em especial os nacionalistas, a noção de que era preciso estimular a P\&D para um fornecimento autônomo e não dependente das potências externas (Amarante 2004).

\section{O Regime Civil-Militar}

As políticas industriais desenvolvimentistas foram retomadas nos governos militares, adotando a concepção supracitada que interligava o desenvolvimento à Segurança e ordem interna, bem como à Defesa Nacional, 
priorizando especificamente a integração com as mudanças tecnológicas em curso na época (Leopoldi 2000). No projeto "Brasil Grande Potência", o Estado, visto como fonte propulsora da capacitação tecnológica e do incremento da autonomia brasileira, adotou uma estratégia de "crescimento industrial com endividamento", na qual favoreceu o crescimento da grande empresa pública e privada, que tinha grande poder de influência nos processos decisórios, mas o Estado enfrentou dificuldades na implementação de projetos de infraestrutura que aprofundaram o endividamento, além de ter falhado em prover desenvolvimento social (Leopoldi 2000; Pedone 1989).

Neste período, empresas oriundas da construção pesada consolidaram-se com grande influência nas políticas públicas do regime, recebendo incentivo e proteção estatal na forma de isenções, empréstimos, contratos e auxílio direto da diplomacia brasileira, começando os seus processos de internacionalização e exportação de suas atividades (Campos 2012, 507). Já o setor de Defesa teve grande desenvolvimento: a Embraer, por exemplo, que foi criada a partir da P\&D de instituições da Aeronáutica durante os anos 1950, entregou 68 aeronaves em 1982, um crescimento de mais de 380\% em relação ao número de aeronaves em 1973 (Gargiulo 2008).

Drumond exemplificou o sucesso da interação Estado-empresas ao dizer que "a construção aeronáutica no Brasil não teria alcançado resultados extraordinários sem o apoio direto do Estado, que continuou apostando na capacidade de engenharia brasileira” (2014, 91). A produção aeronáutica permitiria nova infraestrutura industrial, novos conhecimentos estratégicos e aumentaria as possibilidades de inserção no mercado internacional (Drumond 2014, 95).

Para manter a escala de produção, as exportações dos produtos de Defesa se constituíram como uma importante ferramenta para o desenvolvimento do setor, além de diminuir importações nacionais dos produtos de Defesa. Com apoio do Estado (ou, no caso das empresas estatais, com a ação direta do mesmo), as empresas fecharam seus primeiros contratos de exportação na década de 1970, concedendo a esse setor industrial grande avanço no mercado internacional (ABDI 2011).

No início dos anos 1970, o crescimento nas exportações de sistemas de armas de 1973 a 1984 permitem inferir que as exportações totais da BID tiveram grande aumento. Só a empresa privada Avibras, de aeronáutica, exportou US\$ 350 milhões em equipamentos e serviços em 1987, somando uma receita de US $\$ 1$ bilhão em vendas totais (Drumond 2014, 126). A té o fim do regime, a Indústria de Defesa contava com pleno suporte do Estado e encontrava-se em seu auge, como Amarante ressalta: “a BID brasileira completou a sua atual configuração, com uma infraestrutura de P\&D composta por segmentos público-privados” (2012). 


\section{Redemocratização e anos 90}

Entretanto, o período posterior ao regime militar foi caracterizado pela reversão das políticas industriais e do referencial desenvolvimentista, tanto para a indústria em geral (Leopoldi 2000) como para a expansão da indústria de Defesa em específico (ABDI 2011). O endividamento do período militar levou a uma crise da dívida externa que, junto da inflação e da crise fiscal do Estado, fez com que os empresários, entre eles rentistas e alguns setores dos industriais, aderissem à perspectiva neoliberal que se propagou nos anos 1980 e se consolidou como um consenso nos anos 1990.

A partir do Governo Sarney (1985-1990), o Estado passou a diminuir o seu papel na economia, buscando maior competitividade e reestruturando as empresas através do fim do protecionismo industrial tradicional das décadas anteriores $^{3}$ (Leopoldi 2000). Na década de 1990, os governos buscaram uma orientação neoliberal: diminuindo gastos, abrindo a economia às importações de manufaturados, quebrando a reserva de mercado de setores industriais, privatizando empresas estatais e desregulamentando grande parte da economia brasileira de modo a se abrir ao capital e investimento estrangeiros, levando a retração industrial (Leopoldi 2000).

A indústria de defesa foi diretamente afetada pelas mudanças no cenário doméstico e internacional. Pelo lado externo, o fim do conflito entre o bloco capitalista e o bloco socialista e o desmantelamento da União Soviética fizeram com que arsenais acumulados enchessem o mercado internacional a preços mais baixos (Amarante 2004). Pelo lado interno, o governo deixava de priorizar os gastos e compromissos com as FAs e a Defesa, associados à memória do regime ditatorial, além de desmontar estruturas econômicas e barreiras de proteção industrial aos mais diversos setores produtivos, enfraquecendo a indústria nacional frente à concorrência internacional, sem iniciativas que protegessem ou minimizassem as perdas dessa indústria estratégica (Drumond 2014, 127).

Os dois lados ocasionaram retração da demanda, levando à baixa escala empresarial produtiva e financeira, gerando uma crise na BID caracterizada por falência de empresas, restrição de atividades e investimentos com sucateamento da estrutura produtiva, ociosidade das linhas de produção e, nas empresas privadas sobreviventes, a diversificação de atividades para outros setores industriais, com diminuição de produção para Defesa (ABDI 2011). O gráfico a seguir retrata o comércio exterior de armamentos do período de vinte anos, de 1983 a 2002, englobando desde a redemocratização até o último ano do governo Fernando Henrique Cardoso (FHC).

Segundo Amarante (2004), os anos 1990 promoveram quase um "aniquilamento” da indústria de defesa brasileira. Esse período marca a influ- 
ência da (falta de) ação do Estado para com a indústria de defesa, pois o governo optou, no início dos anos 1990, por não atuar como substituto dos mercados externos, ainda que temporário, o que poderia viabilizar a manutenção da indústria (Moraes 2012).

Entretanto, o desenrolar dos anos 1990 e a fragilidade da Defesa brasileira suscitou em lideranças políticas a necessidade de se reestruturar as atividades de defesa, incluindo sua indústria. FHC alimentou expectativas com seu discurso de que prestaria atenção à modernização e reequipamento das Forças Armadas para condizer com a posição estratégica do Brasil (Drumond 2014, 163), mas, no plano prático, pouco foi priorizado (Drumond 2014, 166).

$\mathrm{O}$ único esforço da gestão FHC após a criação do MD foi, no último mês de 2002, o lançamento da Política e Diretrizes de Compensação Comercial, Industrial e Tecnológica do Ministério da Defesa, o offset, tornando as compensações contratuais obrigatórias, ou seja, positivando uma política pública compensatória que busca promover a competitividade internacional através da modernização tecnológica subordinada às situações de compras públicas (Serrão, Pacheco e Pedone 2014).

\section{Os anos 2000}

O início da gestão Lula em 2003 alterou não só o referencial de desenvolvimento como o processo de declínio do setor de Defesa no Brasil. Em termos de paradigma, após o malogro dos anos 1990, o governo Lula consolidou o Estado logístico, do qual FHC já havia feito um ensaio: o Estado que cria as bases, condições e instrumentos de apoio para atuação do empresariado, ao qual ficam delegadas as responsabilidades empreendedoras, de modo a inserir a economia nacional no mundo globalizado (Cervo e Bueno 2012, 489).

A gestão Lula procurou alinhar demandas das FAs com os empresários da BID, de modo a criar as políticas públicas para o setor e então reorganizou a indústria de defesa em novo modelo (Drumond 2014, 209), buscando revitalização da BID. Para isso, incentivou a BID através de cinco instrumentos:

\section{a) Fortalecimento do Arcabouço Político Específico: Política Pública de Defesa}

O Governo Lula empreendeu esforço em atualizar os conceitos de defesa e segurança para o Brasil no século XXI. Os lançamentos da II PDN, da PNID, da END e do LBDN possuem em comum a positivação de propostas políticas das gestões de governo para a Defesa Nacional brasileira, 
servindo como a base da política pública de defesa que ancora as ações posteriores relacionadas ao tema.

A defesa adquiriu maior espaço na agenda pública, fomentando a percepção da necessidade da intervenção do governo na temática da defesa junto às principais instituições do processo político e à sociedade civil. A forma como essa questão pública se intensificou na agenda política pode ser observada na maior participação civil no debate de diretrizes que cada documento apresenta em relação ao seu antecessor, incluindo nessa questão a participação dos empresários no Fórum Industrial de Defesa. Isso constituiu arcabouço político sobre o qual se dão todas as medidas de incentivo do governo à indústria de defesa e que ofereceu ao setor privado brasileiro uma perspectiva dos esforços e projetos programados para a indústria de Defesa.

\section{b) Inserção da Defesa na Política Industrial}

Para atender às diretrizes de fomento da indústria de defesa, a gestão Lula, em seu segundo mandato, colocou o setor como parte da Política de Desenvolvimento Produtivo (PDP) em 2008. Da mesma forma, a gestão Dilma inseriu a BID no Plano Brasil Maior (PBM) em 2011. Ambos se configuraram como os maiores programas de política industrial, tecnológica e comercial de suas respectivas gestões.

Em ambos os programas observa-se que, em específico para o complexo de defesa, foram elencadas medidas voltadas para ampliação e regulamentação de compras governamentais; ampliação de recursos para PD\&I e formação de recursos humanos; adequação da legislação de exportações de Prodes, além de oferecimento de contrapartidas e garantias para as operações; parcerias internacionais; e promoção da BID em feiras nacionais e internacionais. Grande parte das medidas já foi operacionalizada.

A integração da política para indústria da defesa com os planos de política industrial nacional reverteu a tendência das gestões anteriores, dando foco especial às iniciativas para o setor, com metas e acompanhamento das ações do governo. Ao integrar a política pública de defesa com a industrial, estabelecer o consenso dentro dos agentes de governo (que respaldaram o PDP e o PBM) e delegar cada medida a órgãos distintos da administração pública, ${ }^{4}$ o governo iniciou formalmente o processo de execução das iniciativas previstas na Estratégia Nacional de Defesa.

\section{c) Programas de Compras Públicas}

As aquisições de governo para a defesa estão intimamente ligadas às capacidades de defesa desejadas pelo Estado. Além disso, ao reequipar 
ou modernizar suas Forças Armadas, o Estado com seu poder de compra tem também a capacidade de influenciar a indústria de Defesa, nacional ou estrangeira. O novo paradigma político para a BID brasileira priorizou a ampliação das compras nacionais e o reaparelhamento das FAs como ações estratégicas para revitalização. O governo se dispôs a desenvolver mais de 12 programas de compras de equipamentos militares, em projetos posteriormente agrupados em um Plano de Articulação de Equipamentos de Defesa (Paed), ${ }^{5}$ que seria instrumento do Estado para garantir o fornecimento dos meios que as FAs necessitam e a infraestrutura para provê-los.

A quase totalidade dos programas formulados pelo governo envolvem compras de produtos de empresas da BID, seja na recuperação imediata da capacidade operacional (com a compra de armas, munições, uniformes) ou no desenvolvimento e aquisição de equipamentos militares (caças, helicópteros, submarinos, navios-patrulha, blindados, sistemas de monitoramento, sistemas de mísseis, sistemas de controle do espaço aéreo, entre outros).

Em valores de 2012, isso significou uma demanda prevista de mais de US $\$ 206$ bilhões pelos próximos 40 anos (ou $\mathrm{R} \$ 404$ bilhões). ${ }^{6}$ Em valores corrigidos para 2015, essa mesma demanda seria cerca de $\mathrm{R} \$ 679$ bilhões. $^{7}$ Esse incentivo pode ser crítico para as empresas privadas da base de defesa, pois aumenta internamente a demanda por produtos de defesa e, portanto, as oportunidades de novos negócios.

A expansão dos programas de defesa aumentou o número de licitações e contratos com empresas nacionais para execução dos projetos. Em 2009, ano seguinte à END e ao PDP, já se observou aumento de $41 \%$ nos investimentos totais (de $\mathrm{R} \$ 3,4$ bilhões a $\mathrm{R} \$ 4,8$ bilhões). Neste mesmo ano, a empresa Odebrecht, em associação com a francesa DCNS, fechou o contrato do Programa de Desenvolvimento de Submarinos (Prosub), para aquisição de submarinos convencionais e desenvolvimento conjunto Brasil-França de um submarino nuclear, em Itaguaí, Rio de Janeiro. Em 2010, o orçamento de investimento dirigido ao Comando da Marinha saltou de $\mathrm{R} \$ 1,4$ bilhão para $\mathrm{R} \$ 3,7$ bilhão (aumento de $175 \%$ ).

Também cabe ressaltar a importância da Lei n. 12.598 de 2012, que estabelece condições de compras do Estado em defesa. A legislação prioriza empresas nacionais no fornecimento de produtos de defesa (Prodes) e torna obrigatório que os produtos estratégicos de defesa (PEDs) sejam fornecidos por empresas brasileiras (Brasil 2012).

A política de compras do Estado envolve criar um mercado que não existiria espontaneamente, em face de uma situação de falha de mercado, por razões naturais ou adversas (Eliasson 2010). Ou seja, ela envolve definir o governo como um consumidor substituto (no caso da defesa, um 
dos únicos consumidores) de bens e serviços para representar a demanda por Defesa Nacional da sociedade civil. Numa segunda etapa, a política de compras envolve o desenvolvimento da economia empresarial, já tendo fomentado o mercado como consumidor substituto.

\section{d) Financiamento à Indústria de Defesa}

As incertezas e falta de respaldo aos investimentos feitos pela Indústria de Defesa constituem uma das maiores preocupações do setor privado, "visto que não há contrapartida em garantia de compras, o que coloca em risco a conclusão dos projetos e traz prejuízos irreversíveis à indústria” (Comdefesa 2013).

O governo esteve a par da situação, prevendo na Estratégia Nacional de Defesa que um dos desafios para a BID era a deficiência nos programas de financiamento para as empresas nacionais fornecedoras de produtos de defesa, o que as prejudicava nos mercados interno e externo, e previu medidas para aperfeiçoar as linhas de crédito para o setor (Brasil 2008). Com isso, foram acrescentadas ações tanto na PDP quanto no PBM voltadas para adequação do financiamento às empresas.

O BNDES e a Finep se consolidaram como principais agências públicas de financiamento à BID, especialmente através de financiamentos transversais da PD\&I, da capacidade industrial produtiva e das exportações (Schmitt 2015). Em 2013, visando o aperfeiçoamento do financiamento ao setor como previsto nas políticas públicas para a Defesa, o Governo Dilma lançou o Plano Inova Aerodefesa como um dos seis setores estratégicos do Plano Inova Empresa. ${ }^{8}$ Segundo a Finep, o Inova Aerodefesa foi o plano de maior demanda entre os seis setores específicos, com a demanda total de $\mathrm{R} \$ 13$ bilhões, mais de quatro vezes maior que o orçamento previsto (Finep 2013). Ao todo, 272 entidades foram selecionadas para o processo do Plano (117 empresas parceiras, 77 empresas líderes e 78 ICTs), somando R $\$ 12,8$ bilhões em pedidos de financiamento (Finep 2013). Ao final, o plano disponibilizou o total de $\mathrm{R} \$ 8,7$ bilhões em recursos (Fundo Aeroespacial e Inova 2015).

Percebe-se, portanto, um esforço dos órgãos públicos em oferecer financiamentos mais adequados às características e necessidades da Indústria de Defesa, apesar de ainda estarem em descompasso com a efetiva demanda do setor, conforme sinalizou a comparação no Plano Inova Aerodefesa entre o orçamento inicialmente previsto ( $\mathrm{R} \$ 2,9$ bilhões), o demandado ( $\mathrm{R} \$$ 13 bilhões) e o efetivado ( $\mathrm{R} \$ 8,7$ bilhões). 


\section{e) Regime Tributário e Regulatório Especial}

A carga tributária que recai sobre a indústria de defesa é queixa constante do setor privado (Comdefesa 2011). O ambiente tributário favorecia a importação de equipamentos militares em detrimento da produção interna: a importação de material sob respaldo da Lei n. 8.032 de 12 de abril de 1990 fica com isenção de impostos de importação, enquanto indústria de defesa brasileira era taxada ao longo de toda sua cadeia produtiva, com tributos como ICMS, ISS, PIS/Pasep, Cofins, IPI e II, ${ }^{9}$ cujas alíquotas somadas podem equivaler a mais de $40 \%$ do produto brasileiro de defesa (Comdefesa 2011).

Uma das ações destacadas na END para a renovação da BID foi buscar um regime tributário especial para o setor, para protegê-lo das pressões de imediatismo mercantil (Brasil 2008). As primeiras suspensões significativas de tributos foram para a indústria aeroespacial através do Regime Especial para a Indústria Aeronáutica Brasileira (Retaero), instituído em 2010. Com isso, as empresas que produzem bens ou serviços relacionados à industrialização de aeronaves têm os tributos PIS/Pasep, Cofins e IPI suspensos em casos de venda no mercado interno ou importação (Brasil 2010). O Retaero, no entanto, foi referente apenas ao setor de outros veículos aéreos, sem atingir toda a extensão da base industrial de defesa. Com isso, o setor privado ficou na expectativa do Regime Especial Tributário para a Indústria de Defesa (Retid), conforme sinalizava o Comdefesa/Fiesp, que participou junto do MD na formulação do regime para eliminar as assimetrias tributárias e garantir mais competitividade do produto nacional face ao importado (Comdefesa 2011).

O Retid só foi sancionado pela gestão Dilma em 2012, através da Lei n. 12.598. A legislação positivou a definição do Produto de Defesa (Prode), do Produto Estratégico de Defesa (PED), e da Empresa Estratégica de Defesa (EED), para poder definir quais seriam as características das empresas e produtos que seriam beneficiados pelo regime tributário especial. No tocante ao Retid, a Lei n. 12.598 também suspende, em casos de vendas no mercado interno ou de importação, o PIS/PASEP, o COFINS e o IPI (Brasil 2012). O ICMS, imposto estadual, ficou de fora da suspensão.

Essa era uma demanda do setor privado, que reagiu bem à nova legislação: em estudo do Ipea, $51 \%$ das empresas da BID pesquisadas esperavam impacto extremamente ou muito benéfico do Retid, enquanto a minoria de $21 \%$ achava que o Retid traria pouco ou nenhum impacto (Ipea 2013). A redução nos impostos incidentes nos produtos de defesa significa uma redução de custos nas compras e vendas de Prodes, possibilitando que esse ônus seja retirado do preço final e tornando, portanto, os produtos nacionais mais competitivos. 
A Lei n. 12.598/12 também moldou a criação das subsidiárias de conglomerados. A condição para habilitação de empresa como EED, para se beneficiar de incentivos fiscais do Retid, era que a finalidade da empresa fosse a defesa, pois o faturamento voltado para essa atividade deveria ser no mínimo $70 \%$ do faturamento total, sem controlador estrangeiro. Isso forçou os grupos empresariais que quisessem se beneficiar do Retid a abrirem subsidiárias nestes parâmetros, além de que os editais de compras públicas militares do governo dariam vantagens às EEDs.

Além disso, essa nova legislação dispensou a necessidade de licitação nos setores de ciência e tecnologia das compras públicas de defesa, com vistas a facilitar a entrada de grandes conglomerados brasileiros no setor (Mattioli apud Fariello 2012). Dessa forma, a contratação é agilizada e os procedimentos formais de uma licitação pública, por razão de interesse público, ficam dispensados.

Os incentivos dos dois mandatos de Lula e do primeiro mandato de Dilma deram novo fôlego à indústria de defesa, que atraiu a atenção de empresas estrangeiras e inclusive de grandes conglomerados nacionais. Um dos líderes empresariais na BID, Carlos Erane de Aguiar, ${ }^{10}$ declarou que

Não apenas a indústria de defesa e segurança enxerga estes projetos [de public procurement] como oportunidades de crescimento. Outros segmentos industriais, como construtoras, desenvolvedoras tecnológicas - software, principalmente -, laboratórios de pesquisa de matérias e químicos, estaleiros, metalurgias e indústrias metalomecânicas e tantos outros também estão, cada vez mais, enxergando os projetos de defesa como grandes oportunidades não apenas de crescimento econômico, mas também de evolução tecnológica e de processos produtivos, o que permite abrir mercados internacionais (Erane apud Leite 2015).

Sua visão pode corroborar a tese de que as empresas perceberam os incentivos do governo e os programas de compras públicas como fomentadores de ambiente de negócios mais propício e com mais oportunidades para a inserção de empresas. Além disso, como Erane citou, as empresas também poderiam enxergar outros fatores além dos contratos bilionários e incentivos cenouras para se inserir no mercado de defesa e segurança. Empresas como Odebrecht, Andrade Gutierrez e Engevix inseriram-se no setor de defesa buscando novas oportunidades de negócios, beneficiando-se dos incentivos fiscais e das linhas de financiamento lançados pelo governo, ganhando contratos milionários, absorvendo tecnologia de empresas estrangeiras e desenvolvendo a BID. 


\section{Crise Fiscal de 2014}

A conjuntura doméstica e internacional durante o primeiro Governo Dilma (2011-2014) levou ao estouro, no início de 2015, de uma crise fiscal que forçou o segundo Governo Dilma a adotar política de austeridade, com redução de gastos do governo para gerar superávit primário, e consequentemente diminuiu a parcela orçamentária dedicada a Defesa no Brasil. Os investimentos diminuíram e geraram imprevisibilidade quanto ao prosseguimento da política pública de defesa, traçada pela II PDN, END e LBDN.

$\mathrm{O}$ anúncio de corte (entre $\mathrm{R} \$ 3,5$ a 4,5 bilhões) no orçamento de projetos de defesa e a possível extinção do PAC do setor pelo governo federal criou uma onda de pânico no principal polo da BID no Brasil, em São José dos Campos (Ottoboni 2014). Em 2015, R\$ 5,6 bilhões do orçamento do Ministério da Defesa (25\%) foram contingenciados pelo ajuste (Brasil 2015). A indústria de defesa passou a contar com atrasos na liberação de recursos públicos para pagamento dos contratos e as empresas relacionadas começaram a adiar datas de entregas de produtos, a atrasar salários dos funcionários, como foi o caso da Avibrás, ou mesmo a perder mão de obra (Ottoboni 2015).

Com a crise fiscal de 2014, o contingenciamento de recursos dos programas de defesa e os desdobramentos das investigações de corrupção envolvendo os conglomerados que haviam se inserido na BID, é perceptível um reposicionamento do setor. No programa do Sisgaaz, por exemplo, mesmo com prorrogação de inscrição de candidaturas, os únicos consórcios a se apresentarem foram aqueles liderados por Embraer, Odebrecht e Orbital Engenharia - ficaram de fora Andrade Gutierrez (que tinha proposta com a Rustcon), Queiroz Galvão (em consórcio com Lockheed Martin e Rockwell Collins), Engevix e OAS (Düring 2015).

As restrições orçamentárias pós-2015, com incertezas sobre os incentivos, dentre eles o pagamento e continuidade dos programas militares, permitem demonstrar o impacto da redução de incentivos e investimentos na indústria de defesa afetando diretamente o comportamento dos conglomerados e do setor privado na BID.

\section{CONCLUSÕES}

Este presente estudo se propôs a avaliar o impacto das cenouras de incentivo governamental no desenvolvimento da Indústria de Defesa a partir de uma análise histórica dessa relação no Brasil. Para isso, a pesquisa verificou os efeitos dos incentivos para a Indústria de Defesa ao longo de 
sete períodos recentes da história brasileira: o período anterior ao Governo Vargas, a Era Vargas, os anos 50, o regime civil-militar, a redemocratização e os anos 90, os anos 2000 e o período da crise fiscal de 2014.

É necessário ressaltar as limitações que o estudo enfrentou, pois as informações específicas relacionadas a Defesa são de caráter estratégico e, portanto, mantidas sob sigilo pelo Estado. Da mesma forma, muitas das informações corporativas dos conglomerados são de caráter confidencial e não são divulgadas para não afetar sua atuação no mercado. Mesmo com essas ressalvas, a pesquisa levantou informações importantes que permitiram análise da relação entre incentivos e inserção dos conglomerados no setor de defesa.

$\mathrm{Na}$ análise histórica da Indústria de Defesa do Brasil, pôde-se perceber padrões de avanços e recuos na BID de acordo com o apoio e investimento dos governos. A indústria manufatureira, em geral, era inibida até a Era Vargas e os produtos de defesa eram supridos por importações e montagens nos arsenais militares. A partir do momento em que a indústria nacional passou a ser priorizada, bem como a substituição de importações para redução de dependência externa, a indústria de defesa incipiente pôde iniciar sua expansão, consolidando-se no período da ditadura militar. Nestes anos, a BID foi estimulada para fins de soberania nacional e alcançou grande infraestrutura de $\mathrm{P} \& \mathrm{D}$ e desenvolvimento produtivo como consequência, inclusive elevando as exportações e diminuindo significativamente as importações (nos anos 1980, 90\% dos equipamentos militares eram supridos nacionalmente [Drumond 2014]). De forma similar, no setor de infraestrutura, as empresas de construção se beneficiaram de incentivos do governo para se expandirem neste período, com relação próxima aos agentes públicos (Campos 2012, Pedone 1989).

Contudo, quando o Estado, nos anos 1990, retirou as medidas de incentivo, proteção e demanda para a BID, o setor de defesa brasileiro chegou à situação de sucateamento, com grandes empresas fechadas e as FAs mal equipadas.

As medidas de incentivo posteriores a 2003, inseridas na estratégia de governo de revitalização da BID, serviram como um novo fôlego para a indústria de defesa, inclusive servindo como instrumentos de atração de grandes conglomerados para esta base industrial.

Em suma, o estudo encontrou evidências de que as cenouras criadas pelo governo para incentivar a indústria de defesa desempenharam função fundamental no desenvolvimento do setor. Esses indícios possibilitam reforçar a necessidade do debate sobre incentivo público constante à pesquisa, desenvolvimento e produção da Indústria de Defesa como forma de desenvolvimento da economia deste setor de alto valor agregado. 
Dadas as características específicas desse setor estratégico e conforme observado no estudo, torna-se imperativo que as políticas públicas tenham foco na manutenção ou expansão do orçamento para o setor, aliadas a instrumentos regulatórios e econômicos que equalizem a competição entre a indústria nacional e a estrangeira. Com isso, seria possível preservar a demanda industrial enquanto se melhora o ambiente de negócio da base nacional da Indústria de Defesa, aspectos que se destacaram em políticas de revitalização desta indústria.

\section{REFERÊNCIAS}

ABDI. Agência Brasileira de Desenvolvimento Industrial. 2011. Diagnóstico: Base Industrial de Defesa Brasileira. Campinas: NEIT-IE-UNICAMP.

Amarante, J. C. A. 2004. Indústria Brasileira de Defesa: uma questão de soberania e de autodeterminação. In: Pensamento Brasileiro sobre Defesa e Segurança: as Forças Armadas e o Desenvolvimento Científico do País. 3, 23-44. Brasília: Ministério da Defesa.

Amarante, J. C. A. A Base Industrial de Defesa Brasileira. Texto para discussão. Instituto de Pesquisa Econômica Aplicada - IPEA: Brasília : Rio de Janeiro, 2012.

Brasil. 2008. Estratégia Nacional de Defesa. Decreto n ${ }^{\circ}$ 6.703, 18 dez. 2008. Brasília.

Brasil. 2010. Lei nº 12.249, 11 jun. 2010. Brasília.

Brasil. 2012. Lei n 12.598, 21 mar. 2012. Brasília.

Brasil. Ministério da Defesa. Nota à Imprensa: Contingenciamento 2015. Brasília, 22 mai. 2015. Disponível em: http://www.defesa.gov.br/noticias/15811-nota-a-imprensa-contingenciamento-2015-ministerio-da-defesa. Acesso em: 20 dez. 2015.

Brick, E. 2014. O Mercado das Empresas da Associação Brasileira das Indústrias de Materiais de Defesa e Segurança - ABIMDE. Relatórios de Pesquisa em Engenharia de Produção, Niterói, 14 (D6), 91-149.

Campos, P. H. P. 2012. A Ditadura dos Empreiteiros: as empresas nacionais de construção pesada, suas formas associativas e o Estado ditatorial brasileiro, 1964-1985. [Tese de Doutorado em História] 539 p. Niterói: ICHF/UFF.

Cervo, A., Bueno, C. História da política exterior do Brasil. $4^{\mathrm{a}}$ Edição. Brasília: Editora Universidade de Brasília, 2012.

Comdefesa - Departamento da Indústria de Defesa. 2013. Análise Comdefesa: O Investimento na Defesa Nacional. Fiesp: São Paulo. 
Comdefesa - Departamento da Indústria de Defesa. 2011. Análise Comdefesa: Por que é importante definir Produto Estratégico de Defesa? Fiesp: São Paulo.

Dreyfus, P., Lessing, B., Purcena, J. C. 2005. A indústria brasileira de armas leves e de pequeno porte: produção legal e comércio. In: Fernandes, R. C. (Coord.). Brasil: as armas e as vítimas. Rio de Janeiro: 7Letras.

Drumond, C. D. 2014. Indústria de Defesa do Brasil: História, Desenvolvimento, Desafios. Guarulhos: ZLC Comunicação.

Düring, N. 2015. SisGAAz Exclusive - Three Main Contractors, assemble!. Defesanet, Cobertura Especial. Brasília. Disponível em: <http://www.defesanet. com.br/sisgaaaz/noticia/18064/SisGAAz-Exclusive-\%E2\%80\%93--Three-Main -Contractors--assemble-/>. Acesso em: 2 jan. 2016.

Eliasson, G. 2010. Advanced Public Procurement as Industrial Policy: the aircraft industry as technical university. Nova York: Springer.

Fariello, D. 'Haverá união das grandes empresas': Colaboração do setor privado ajudará indústria bélica no Brasil, diz general. O Globo, 15 jul. 2012. Disponível em: http://oglobo.globo.com/economia/havera-uniao-das-grandes-empresas-5481561\#ixzz41T8kaH90 Acesso em: 26 fev. 2016.

Finep. Workshop Inova Aerodefesa: Abertura e balanço da primeira etapa. Hudson Lima Mendonça. Apresentação. São Paulo: 27 ago. 2013.

Fundo Aeroespacial e Inova Aerodefesa fazem os primeiros investimentos. Portal do APL de Defesa do Grande ABC, 11 jun. 2015. Disponível em: http://www. industriadefesaabc.com.br/site/financiamento-fundo-aeroespacial-e-inova-aerodefesa-fazem-os-primeiros-investimentos/ Acesso em: 20 set. 2015.

Furtado, C. 1995. Formação Econômica do Brasil. 25. ed. São Paulo: Companhia Editora Nacional.

Gargiulo, F. 2008. Indústria de Construção Aeronáutica, o Caso da EMBRAER: História e Avaliação. Dissertação em Finanças e Economia Empresarial. Rio de Janeiro: FGV.

Hartley, K. 1999. O Futuro da Política de Aquisições na Indústria Europeia de Defesa. Nação e Defesa, 90, 2º́rie, 17-34.

Ipea - Instituto de Pesquisa Econômica Aplicada. 2013. Base Industrial de Defesa Brasileira: Características das Firmas e Percepção dos Empresários do Setor. Nota Técnica $n^{\circ} 10$. Brasília. 
Leite, H. 2015. Foco na Defesa: Entrevista com Carlos Erane de Aguiar. Aerovisão, 245 (42), 8-11.

Leopoldi, M. A. P. 2000. Política e interesses: as associações industriais, a política econômica e o Estado na industrialização brasileira. São Paulo: Paz e Terra.

Moraes, R. A inserção externa da indústria brasileira de defesa: 1975-2010. Brasília: IPEA, 2012. (Texto para discussão 1715). Disponível em: http://www.ecsbdefesa. com.br/defesa/fts/TD1715.pdf . Acesso em: 20 jul. 2015.

Mowery, D. 2012. Defense-related R\&D as a model for "Grand Challenges" technology policies. Research Policy, 41 (10), 1703-1715.

Ottoboni, J. Cortes Orçamentários criam pânico na Base Industrial de Defesa. Defesanet, 26 fev. 2014. Disponível em: http://www.defesanet.com.br/bid/ noticia/ 14337/DEFESA-\%E2\%80\%93-Cortes-Orcamentarios-criam-panicona-Base-Industrial-de-Defesa/ Acesso em: 20 dez. 2015.

Ottoboni, J. Situação é gravíssima e divergências no MD. Defesanet, 26 fev. 2015. Disponível em: http://www.defesanet.com.br/bid/noticia/18279/ AVIBRAS- $\%$ E2\%80\%93-Situacao-e-gravissima-e-divergencias-no-MD/ Acesso em: 20 dez. 2015.

Pacheco, T. 2016. O Impacto dos Incentivos na Expansão e no Declínio da Indústria de Defesa Brasileira: O Caso da Inserção de Grandes Conglomerados. Março de 2016. 114 p. Monografia. Universidade Federal Fluminense, Niterói, 2016.

Pedone, L. 1989. State autonomy, political power and public policy: a study of Brazilian development. Tese de Doutorado em Ciência Política. Amherst: University of Massachussetts-Amherst.

Schmitt, S. 2015. BNDES apresenta financiamentos disponíveis para a defesa. Entrevista. 27 ago. 2015. Indústria de Defesa \& Segurança. Disponível em: $<$ http://defesaeseguranca.com.br/entrevista-sergio-schmitt-engenheiro-da-area-industrial-do-bndes/>. Acesso em: 20 set. 2015.

Serrão, N., Pacheco, T., Pedone, L. The Offset Policy Evaluated through the $\mathrm{HX}-\mathrm{Br}$ Compensatory Perspective. In: XXXVIII EnANPAD (Encontro da Associação Nacional de Pós-Graduação e Pesquisa em Administração), 2014, Rio de Janeiro. EnANPAD, 2014.

Skidmore, T. 2007. Brasil: de Getulio a Castelo. 14. ed. Rio de Janeiro: Paz e Terra.

Vianna, S. 1989. Política Econômica Externa e Industrialização: 1946-1951. In: Abreu, M. (Org.). A Ordem do Progresso. Campinas: Editora Campus. 


\section{NOTAS}

1. Por exemplo, o Departamento da Indústria de Defesa da Federação das Indústrias de São Paulo (Comdefesa/Fiesp), entidade representativa do setor privado paulista, argumenta que o descompasso orçamentário que impede o planejamento estratégico de governo e indústria - e a dificuldade em obter investimentos em Defesa - que pode prejudicar a conclusão de projetos de $\mathrm{P} \& \mathrm{D}$ em vista da ausência de garantia de compras - são entraves para o setor produtivo se preparar e ser autossustentável (Comdefesa 2013).

2. Bens econômicos que servem para a produção de outros bens, como máquinas, material de transporte, instalações de uma indústria, etc.

3. Uso de mecanismos como tarifa, câmbio e controle de importações.

4. Por exemplo, o Ministério da Defesa, o Ministério da Ciência, Tecnologia e Inovação, a Agência Espacial Brasileira e a Financiadora de Estudos e Projetos (FINEP).

5. Articulado, porém não se tornou lei. O setor privado aguarda também aprovação da Política de Obtenção Conjunta de Produtos de Defesa (POCMD) para padronização da gestão das compras.

6. Cotação do dólar aproximada de US $\$ 1,00=\mathrm{R} \$ 1,96$.

7. Cotação do dólar aproximada de US $\$ 1,00=\mathrm{R} \$ 3,30$.

8. No total, o Inova Empresa previa $\mathrm{R} \$ 33$ bilhões em créditos, subvenções, créditos não reembolsáveis e Fundos de Private Equity.

9. Respectivamente, Imposto sobre Circulação de Mercadorias e Serviços (estadual), Imposto sobre Serviços de qualquer natureza (municipal), Contribuição ao Programa de Integração Social e ao Programa de Formação de Patrimônio do Servidor Público (federal), Contribuição para Financiamento da Seguridade Social (federal), Imposto sobre Produtos Industrializados (federal), Imposto de Importação (federal, aplicável no caso de insumos).

10. Presidente do Sindicato Nacional das Indústrias de Materiais de Defesa e presidente do Fórum de Defesa e Segurança da FIRJAN. 


\section{INCENTIVOS GOVERNAMENTAIS E INDÚSTRIA DE DEFESA}

\section{RESUMO}

Este artigo buscou analisar o desenvolvimento da indústria de Defesa e sua relação com os incentivos dos governos brasileiros dos séculos XX e XXI. Objetivou-se verificar se a Indústria de Defesa é vista como um polo de oportunidades para o setor privado brasileiro a partir do momento em que o governo investe e apoia o ambiente de negócios desse setor. $\mathrm{O}$ estudo focou-se em especial nos incentivos dos anos 2010, que levaram as autoridades a formularem políticas públicas voltadas para a Base Industrial de Defesa (BID), como, por exemplo, a Estratégia Nacional de Defesa (2008) e o estabelecimento das Empresas Estratégicas de Defesa (2013). Com as novas iniciativas de estímulo à defesa, grandes grupos empresariais brasileiros, focados em setores diversos como o de Construção Pesada e o de Petróleo e Gás, formaram empresas voltadas para a BID. Dessa forma, levando em conta a importância estratégica da BID, esse trabalho buscou traçar o paralelo causal entre os incentivos governamentais e o desenvolvimento da indústria de defesa.

Palavras-chave: Indústria de Defesa; Incentivos Governamentais; Políticas Públicas; Desenvolvimento do setor privado.

\section{ABSTRACT}

This article analyses the Defense industry development and its relation with the Brazilian governments' incentives during the XX and XXI centuries. We seek to verify if the Defense industry is seen as a pole of opportunities to the Brazilian private sector once the government invests and supports this industry's business climate. In particular, the study focuses on the 2010's incentives, that led the authorities to formulate public policies for the Defense Industrial Base (BID), such as the Defense Industry National Policy (2005), the Defense National Strategy (2008) and the regulation of the Defense Strategic Companies (2013). With the new stimulus initiatives to defense, large Brazilian business groups, focused on many sectors as the Heavy Construction and the Oil \& Gas, have created companies that focus on the Defense Industry. Considering the BID's strategic importance, this article traces a causal parallel between government incentives and Defense industry development.

Keywords: Defense Industry; Government Incentives; Public Policies; Private sector development.

Recebido em: 02/03/2017. Aceito para publicação em: 02/03/2017. 